\title{
Structural Relationships of Environments, Individuals, and Learning Outcomes in Korean Online University Settings
}
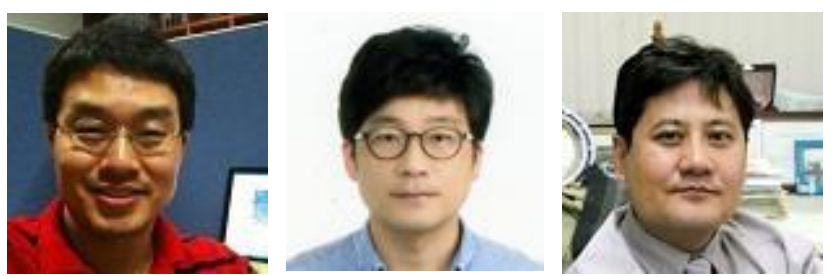

Keol Lim', Minseok Kang ${ }^{3}$, and Sung Youl Park ${ }^{2}$

1,2Konkuk University, Korea, ${ }^{3}$ corresponding author, KyungHee Cyber University, Korea

\begin{abstract}
This study examines relationships of instructional environments, learner traits, and learning outcomes in the context of an online university course in Korea which has an advanced information technology background and rich e-learning experiences. However, the educational heritage of the country adheres to directive instruction with little interaction in the classroom. Based on the literature review, specific research variables are as follows: the environmental variables include learner-learner interaction, learner-instructor interaction, and content/system quality. Regarding learner traits, intrinsic/extrinsic motivation and computer/academic self-efficacy were investigated. Academic achievement and class satisfaction were identified as potential determinants of online learning outcomes. A total of 937 valid responses from online university students were used to establish structural relationships among the variables. Most of the structural associations among the factors were significantly positive, although some variables reflected Korean cultural and educational contexts specifically. The findings suggest a need for a synthetic approach towards e-learning and that further research should be conducted concerning context-specific variables.
\end{abstract}

Keywords: e-learning, online university, Korean education, learning environments, cognitive domain, learning outcomes

\section{Introduction}

As e-learning continues to gain acceptance as a standardized education system, researchers search for valid factors to assist in understanding the effectiveness of e-learning outcomes. Recent trends involve examining to what extent external environments and internal cognitive traits of learners relate to learning outcomes. Prior research has investigated relationships between input, environment, and outcomes (Astin, 1991), human dimensions and design dimensions (Piccoli, Ahmad, \& Ives, 2001), and design, delivery, and outcomes (DeLone \& McLean, 2003). The e-learning success model developed by DeLone and McLean (2003) was later enhanced by Holsapple and Lee-Post (2006) as 
well as Eom (2011).

This study's primary objective is to identify determinants of student learning outcomes and satisfaction in online e-learning systems. To address this issue, we began by establishing a research model based upon earlier studies in order to highlight variables that affect e-learning outcomes and user satisfaction. Furthermore, it is important for readers to understand the context of the study's research environment. Korea possesses an advanced background in information technology (IT), and a strong Internet infrastructure. Accordingly, e-learning has relatively a long history in the country, and learners at all grade levels are to some extent familiar with online education. However, learning in Korea is also heavily influenced by its Asian educational heritage, wherein the intellectual authority of an instructor is highly respected. Teachers are expected to deliver learning content in a unidirectional manner wherein communication or interaction with students is limited (Lee, 2010; Park, 2006).

Following a review of related literature and a discussion concerning Korea's educational background, structural relationships between major learning outcome constructs will be described. These constructs include environmental variables (e.g., interactions during the e-learning process and content/system quality) and cognitive variables (e.g., internal/external motivation and computer/academic self-efficacy). Academic performance and class satisfaction were selected to represent learning outcomes. The sections that follow provide a description of the survey used during the data collection process and the structural equation modeling outcomes.

\section{Background}

\section{Assessment of E-Learning Effectiveness}

Discussions concerning the assessment of e-learning have increased in parallel with technological developments and the heightened use of computers in classrooms. To enrich such discussions, it is essential to identify critical variables for measuring the overall effectiveness of e-learning initiatives. Astin's (1991) Input-Environment-Outcome model is a widely used theoretical framework for assessing e-learning effectiveness. The effectiveness of an e-learning course, according to Astin, is a function of three elements: input, environment, and outcomes. Input variables include student characteristics (e.g., demographic, personal, and academic information), while environmental variables entail things that learners experience while partaking in educational programs, which ultimately influence outcomes. Outcomes encompass the desired aims and objectives of students following the completion of an academic activity. Hence, educational attainment involves interaction between learner characteristics, which consequently influences the relationship between students and their educational environment (Kjelgaard \& Guarino, 2012).

In their study concerning a web-based virtual learning environment, Piccoli, Ahmad, and Ives (2001) identified two dimensions of learning effectiveness: a human dimension and a design dimension. The human dimension from a student perspective consists of factors such as maturity, motivation and attitude; from a teacher perspective, this dimension comprises technological ability, attitude toward technology, and teaching styles. The design dimension consists of factors such as the learning model adopted, the type of technology used, learner control, course content, and student-teacher interaction. Learning effectiveness in Piccoli et al.'s (2001) study was measured according to performance, self- 
efficacy, and learner satisfaction.

DeLone and McLean (1992) developed an information systems success model in which they identified six dimensions for success: system/information quality, ease of use, user satisfaction, and individual/organizational impact. The aforementioned researchers later modified this model to fit an e-learning context by creating an additional dimension (i.e., service quality), and integrated individual/organizational impact into a single dimension (i.e., net benefits) (DeLone \& McLean, 2003). Overall e-learning success in DeLone and McLean (2003)'s revised model was determined according to the attainment of success in three stages of e-learning systems development: design (system quality, information quality, and service quality), delivery (use and user satisfaction), and outcome (net benefits).

Holsapple and Lee-Post (2006) developed their own model for e-learning success based on DeLone and Mclean's model (2003), wherein e-learning success is dependent on system design, system delivery, and system outcomes. Eom (2011) likewise built an e-learning system effectiveness model composed of independent variables (e.g., e-learning system quality, information quality, and computer self-efficacy), and dependent variables (e.g., system use, user satisfaction, self-regulated learning behavior, and e-learning outcomes). This model also included individual constructs as critical elements for estimating e-learning success, such as self-efficacy and self-regulated learning (Eom, 2011).

\section{An Overview of Education and E-Learning in Korea}

Korea is a leading country in IT. According to the Organization for Economic Co-operation and Development (2013), over 95\% of Korean households are on-line, thus ranking it number one among nations in terms of Internet connectivity. In additional to its mature IT infrastructure, Korea also functions as a testbed for the products of global technology companies (BeSuccess, 2014).

Regarding the relationship between Korea's IT and educational sectors, the nation possesses an abundance of experience in online learning dating back to the late 1990s. According to the Korean Ministry of Education (2013), the nation's e-learning industry has generated 2.7 billion dollars in revenue as of 2012. Korean cyber universities have offered bachelor's and master's degree programs since 2001 (CU Info, 2014a). As of 2013, 21 cyber universities are operating in the country, with approximately 100,000 enrollees (CU Info, 2014b).

Korean educational culture has unique characteristics due the historical influence of Confucianism, wherein students are expected to obey the authority of one's teacher (Park, 2006). The extremely competitive nationwide standardized college entrance examination forces teachers to deliver knowledge in a unidirectional manner, thus limiting opportunities for autonomous learning or creative instruction (Hwang, 2004). Under such conditions, cramming and teacher-centered instructional methods continue to thrive (Lee, 2010).

Unfortunately, e-learning instructional environments are not necessarily very different. Korean elearning courseware seldom offers opportunities for interaction, and online lessons are conducted primarily in a lecture form, wherein student discussions or inquiries are rare. There is, however, 
growing interest in identifying more innovative ways to utilize e-learning in light of the new instructional possibilities that have been afforded by Web 2.0 technologies. Practitioners of e-learning have consequently started to seek more efficient and effective e-learning strategies in order to increase opportunities for student-teacher and student-student interactions (Kang \& Park, 2010; Kang \& Lim, 2013).

\section{Contextual Variables for E-Learning Effectiveness}

Environmental variables. First of all, Hirumi (2013) asserts that interactions between/among instructor-student, student-student, and student-content are critical in ensuring online learning effectiveness. Indeed, active learner and instructor participation in e-learning courses is a prerequisite for fostering effective learning (Piccoli et al., 2001).

It should be noted that some of the negative impact of Confucianism on education culture discussed earlier has not only produced a unidirectional teaching style in traditional Korea classrooms, but virtual classrooms as well. Korean e-learning courseware generally requires learners to watch either video or Flash animation tutorials; in such conditions, teacher-student or student-student communication is neglected. Fortunately, Korean researchers, practitioners, and instructors are gradually realizing the significance of interaction, and are consequently attempting to facilitate it in elearning courseware (Choi \& Choi, 2016).

By the way, successful e-learning is dependent on information and system quality-both of which have a profound impact on mediating user satisfaction (DeLone \& McLean, 1992, 2003; Holsapple \& LeePost, 2006). Lin, Chen, and Fang (2011) maintain that attributes such as functional quality (e.g., ease of use and reliability) and instructional quality (e.g., whether users' needs are met) are determinants of user satisfaction. Similarly, Wong and Huang (2011) devised a model wherein service quality, information quality, system quality, and perceived usefulness comprised e-learning system service quality. Their findings revealed a correlation between e-learning system service quality and strengthened learning effectiveness; each of the constructs was significant in relation to organizational learning. Therefore, system/content quality are common and significant elements in relation to elearning effectiveness, and are consequently included in the present study as exogenous variables.

Individual variables. According to DeLone and McLean (1992), system and information quality cause the use of e-learning systems to affect user satisfaction. Accordingly, system use is dependent on learner motivation. Despite the fact that motivation is a crucial variable in explaining learning outcomes, established research has largely ignored motivation's role, since it is assumed that e-learners are active and self-motivated (Nehme, 2010). Therefore, intrinsic and extrinsic motivation is worthy of investigation as a mediating variable in this study.

Self-efficacy. According to Bandura (1993), self-efficacy entails one's belief in his or her ability to succeed in a specific situation. Moreover, a significant positive correlation has been found between academic self-efficacy and academic achievement (Høigaard, Kovač, Øverby, \& Haugen, 2015). Higher academic self-efficacy is also a key predictor of approach goals with regards to learning achievement (Elliot, 2005; Putwain \& Symes, 2012). 
Similarly, computer self-efficacy involves one's perceived ability to use a computer to accomplish a given task in an e-learning environment (Hsiao, Tu, \& Chung, 2012). Positive correlations were found between computer self-efficacy and e-learning effectiveness independent of mediating variables for learning outcomes in numerous studies (Chiu \& Wang, 2008; Johnson, Hornik, \& Salas, 2008; Simmering, Posey, \& Piccoli, 2009). Womble (2008) also identified significant relationships between self-efficacy, learner satisfaction, and the perceived usefulness of e-learning.

Result variables. Class satisfaction and learning achievement have traditionally been among the most efficient constructs for measuring learning effectiveness. Both variables were consequently selected to represent e-learning outcomes in this study, with academic achievement as a dependent variable for class satisfaction. Although it has been established that most relationships between class satisfaction and learning achievement are intertwined, few studies to date have examined their synthetic structure. Therefore, this study utilized a synthetic e-learning effectiveness model comprising both environmental and individual factors in order to determine the predictive validity of both variables, while simultaneously considering the idiosyncrasies of Korea's educational culture.

Many previous studies mainly emphasized fragmentary variables in measuring e-learning effectiveness, and focused on discrete variables such as learning content or the instructor without accounting for input factors such as learner characteristics. The present research model takes both environmental and individual factors into consideration, and also proposes a pathway from environmental to learner characteristic variables. Furthermore, essential elements were selected to effectively represent environmental and individual variables based on a review of prior literature and consideration of the research site's distinct characteristics. Hence, it is expected that this theoretical research model will facilitate a deeper understanding of the causal relationships and pathways that affect the effectiveness of e-learning.

The environmental variables were set as learner-learner interaction, learner-instructor interaction, content quality, and system quality. The individual variables consisted of intrinsic motivation, extrinsic motivation, computer self-efficacy, and academic self-efficacy. The outcomes were set as class satisfaction and academic achievement. Given these variables, the research hypotheses are as follows:

H1: Learner intrinsic motivation is related to learner-learner interaction, learner-instructor interaction, content quality, and system quality.

H2: Learner extrinsic motivation is related to learner-learner interaction, learner-instructor interaction, content quality, and system quality.

H3: Learner computer self-efficacy is related to learner-learner interaction, learner-instructor interaction, content quality, and system quality.

H4: Learner academic self-efficacy is related to learner-learner interaction, learner-instructor interaction, content quality, and system quality.

$\mathrm{H}_{5}$ : Learner class satisfaction is related to intrinsic motivation, extrinsic motivation, 
computer self-efficacy, and academic self-efficacy.

H6: Learner academic achievement is related to intrinsic motivation, extrinsic motivation, computer self-efficacy, academic self-efficacy, and class satisfaction.

\section{Methodology}

\section{Participants}

The study's participants included undergraduate students enrolled in a Korean online university. A survey was distributed to 1,133 students; however, 196 of the returned questionnaires were excluded from analysis due to either empty or identical responses to questions. Thus, 937 valid survey questionnaires were analyzed in addressing the study's research questions. Participant demographics are provided in Table 1.

Table 1

Participant Demographics

\begin{tabular}{|c|c|c|c|c|c|}
\hline \multicolumn{2}{|c|}{ Gender } & \multicolumn{2}{|c|}{ Age (years) } & \multicolumn{2}{|c|}{ Grade } \\
\hline & Number & & Number & & Number \\
\hline Male & 407 & Under 20 & 10 & 1 & 202 \\
\hline \multirow[t]{4}{*}{ Female } & 530 & $20-29$ & 189 & 2 & 154 \\
\hline & & $30-39$ & 264 & 3 & 279 \\
\hline & & $40-49$ & 301 & 4 & 302 \\
\hline & & Over 50 & 173 & & \\
\hline Total & 937 & & 937 & & 937 \\
\hline
\end{tabular}

\section{Instrument}

The questionnaire used in this study was based on commonly implemented and widely accepted surveys in the field, however some items were modified to more appropriately fit the present research context. Three experts in educational technology and measurement assisted in reviewing the questionnaire for face validity. 
To evaluate interactions among learners and between learners and instructors, four items regarding learner-learner interaction, and five items concerning learner-instructor interaction were adopted from a questionnaire designed by An (2008). The Cronbach's alphas for both groups of items were .94. Five items were also adopted from questionnaires developed by Kettinger and Lee (1997) and Lee, Strong, Kahn, and Wang (2002) in order to obtain information pertaining to the quality of learning content. The Cronbach's alpha for these items was .94. To evaluate the quality of online learning systems used by participants, three items were adopted from Gu, Lee, Kim, and Suh (2006); the Cronbach's alpha for these items was .93. As for evaluating extrinsic and intrinsic motivation, five items were adopted from Stein (1997); of these, items two and three possessed a Cronbach's alpha of .80 and .82 respectively.

Three items regarding computer self-efficacy were adopted from Lee (2006), with a Cronbach's $\alpha$ of .83. Likewise, three items concerning academic self-efficacy were adopted from a questionnaire designed by Flowers (2011), with a Cronbach's alpha of .84. As for learning outcomes, three items were adopted from a class satisfaction questionnaire developed by Wang (2003), with a Cronbach's alpha of .92. Regarding perceived academic achievement, four items were adopted from Chemers, $\mathrm{Hu}$, and Garcia (2001) with a Cronbach's alpha of .93. Each questionnaire item was based on a five-point Likert scale wherein $1=$ strongly disagree, $2=$ disagree, $3=$ neutral, $4=$ agree, and $5=$ strongly agree.

\section{Data Collection and Analysis}

Nine hundred and thirty-seven valid survey responses were collected over a ten-day period between January $5-14,2014$, by means of the university's online learning management system. Structural equation modeling was employed to examine the research model hypotheses, and AMOS 18.0 was used to perform data analysis.

\section{Results}

A two-step analysis was first conducted wherein the measurement model was examined in order to determine convergent and discriminant validity. Next, the hypotheses' structural model was assessed using a model of fit indices and by evaluating the model path.

\section{Measurement Model}

Convergent validity. A convergent validity test (Fornell \& Larcker, 1981) was performed comprising three elements: each measure's item reliability, each construct's composite reliability, and the average variance extracted (AVE). The factor loadings for the items were significant (0.686 0.924), and thus obtained convergent reliability. Composite reliability ranged between .845 and .959 , which met the required value of $\geq .7$; likewise, AVE was $>.5$, thus meeting the required value of $\geq .5$.

As for the fit indices, the following results were obtained: $\mathrm{x}^{\wedge} 2 / \mathrm{df}=3.324$; TLI $=.955$; CFI $=.961$; RMSEA $=.050$.

Discriminant validity. Discriminant validity measures the extent to which one construct differs from another and its indicators. A construct's discriminant validity is confirmed when the square root of the AVE exceeds the correlation coefficient between constructs (Segars \& Grover, 1998). Table 2 shows that the square root value of the AVE exceeded the correlation coefficient between 
constructs, hence confirming the research instrument's validity.

Table 2

Correlation Matrices and Discriminant Validity Among Variables

\begin{tabular}{|c|c|c|c|c|c|c|c|c|c|c|c|}
\hline Variable & $\begin{array}{c}\mathrm{AV} \\
\mathrm{E}\end{array}$ & $\begin{array}{c}\text { Learner- } \\
\text { learner } \\
\text { interacti } \\
\text { on }\end{array}$ & $\begin{array}{c}\text { Learner- } \\
\text { instructo } \\
\quad \mathrm{r} \\
\text { interacti } \\
\quad \text { on }\end{array}$ & $\begin{array}{c}\text { Conte } \\
\text { nt } \\
\text { qualit } \\
\text { y }\end{array}$ & $\begin{array}{c}\text { Syste } \\
\text { m } \\
\text { qualit } \\
\text { y }\end{array}$ & $\begin{array}{c}\text { Intrinsic } \\
\text { motivati } \\
\text { on }\end{array}$ & $\begin{array}{c}\text { Extrinsic } \\
\text { motivati } \\
\text { on }\end{array}$ & $\begin{array}{l}\text { Comput } \\
\text { er self- } \\
\text { efficacy }\end{array}$ & $\begin{array}{l}\text { Academ } \\
\text { ic self- } \\
\text { efficacy }\end{array}$ & $\begin{array}{c}\text { Class } \\
\text { satisfacti } \\
\text { on }\end{array}$ & $\begin{array}{c}\text { Academic } \\
\text { achievem } \\
\text { ent }\end{array}$ \\
\hline $\begin{array}{c}\text { Learner- } \\
\text { learner } \\
\text { interactio } \\
\mathrm{n}\end{array}$ & .75 & $.87^{*}$ & & & & & & & & & \\
\hline $\begin{array}{c}\text { Learner- } \\
\text { instructor } \\
\text { interactio } \\
\mathrm{n}\end{array}$ & .78 & .52 & $.88^{*}$ & & & & & & & & \\
\hline $\begin{array}{l}\text { Content } \\
\text { quality }\end{array}$ & .82 & .39 & .76 & $.90^{*}$ & & & & & & & \\
\hline $\begin{array}{l}\text { System } \\
\text { quality }\end{array}$ & .88 & .38 & .65 & .70 & $.94^{*}$ & & & & & & \\
\hline $\begin{array}{c}\text { Intrinsic } \\
\text { motivatio } \\
\text { n }\end{array}$ & .86 & .19 & .34 & .42 & .41 & $.93^{*}$ & & & & & \\
\hline $\begin{array}{c}\text { Extrinsic } \\
\text { motivatio } \\
n\end{array}$ & .70 & .36 & .49 & .57 & .51 & .53 & $.84^{*}$ & & & & \\
\hline $\begin{array}{l}\text { Computer } \\
\text { self- } \\
\text { efficacy }\end{array}$ & .65 & .37 & .42 & .39 & .45 & .34 & .48 & $.81^{*}$ & & & \\
\hline $\begin{array}{l}\text { Academic } \\
\text { self- }\end{array}$ & .70 & .59 & .59 & .45 & .39 & .41 & .54 & .57 & $.84^{*}$ & & \\
\hline
\end{tabular}




\begin{tabular}{|c|c|c|c|c|c|c|c|c|c|c|c|}
\hline efficacy & & & & & & & & & & & \\
\hline $\begin{array}{c}\text { Class } \\
\text { satisfactio } \\
\mathrm{n}\end{array}$ & .85 & .26 & .65 & .82 & .67 & .47 & .56 & .36 & .39 & $.92^{*}$ & \\
\hline $\begin{array}{c}\text { Academic } \\
\text { achievem } \\
\text { ent }\end{array}$ & .84 & .33 & .70 & .83 & .67 & .49 & .57 & .37 & .43 & .91 & $.92^{*}$ \\
\hline
\end{tabular}

* Square root of the AVE

\section{Structural Model}

The goodness of fit for this study's structural regression model is shown in Table 3. Indices for the initial structural model indicated that the model was adequate. Twelve paths were deemed insignificant however, and were therefore removed in order to develop a more simplified model. As for the initial structural model, the following results were obtained: $\left(\mathrm{x}^{\wedge} 2\right)=2202.132(\mathrm{p}<.001) ; \mathrm{x}^{\wedge} 2 / \mathrm{df}$ $=4.171 ; \mathrm{TLI}=.939 ; \mathrm{CFI}=.946 ; \mathrm{RMSEA}=.058$. Regarding the modified structural model, the following results were obtained: $\left(\mathrm{x}^{\wedge} 2\right)=1163.063(\mathrm{p}<.001) ; \mathrm{x}^{\wedge} 2 / \mathrm{df}=3.823 ; \mathrm{TLI}=.959 ; \mathrm{CFI}=.964$; RMSEA $=.055$. Accordingly, the modified model was adopted by this study.

Table 3

Correlation Matrices and Discriminant Validity

\begin{tabular}{llllllll}
\hline & CMIN & $p$ & $d f$ & CMIN/df & TLI & CFI & RMSEA \\
\hline Initial model & 2202.132 & .000 & 528 & 4.171 & .939 & .946 & .058 \\
\hline $\begin{array}{l}\text { Modified } \\
\text { model }\end{array}$ & 1163.063 & .000 & 305 & 3.823 & .959 & .964 & .055 \\
\hline
\end{tabular}

Causal relationships between exogenous and endogenous variables are provided in Figure 1. Specific results for hypotheses testing are as follows: Learner intrinsic motivation was related to content quality and system quality, but not related to learner-learner interaction and learner-instructor interaction (H1). Learner extrinsic motivation was related to content quality and system quality, but not related to learner-learner interaction and learner-instructor interaction (H2). Learner computer self-efficacy was related to learner-learner interaction and system quality, but not related to learnerlearner interaction and content quality $\left(\mathrm{H}_{3}\right)$. Learner academic self-efficacy was related to learnerlearner interaction and content quality, but not related to learner-instructor interaction and system quality ( $\left.\mathrm{H}_{4}\right)$. Learner class satisfaction was related to intrinsic motivation, extrinsic motivation and 
academic self-efficacy, but not related to computer self-efficacy (H5). Learner academic achievement is related to academic self-efficacy, but not related to intrinsic motivation, extrinsic motivation and computer self-efficacy (H6).

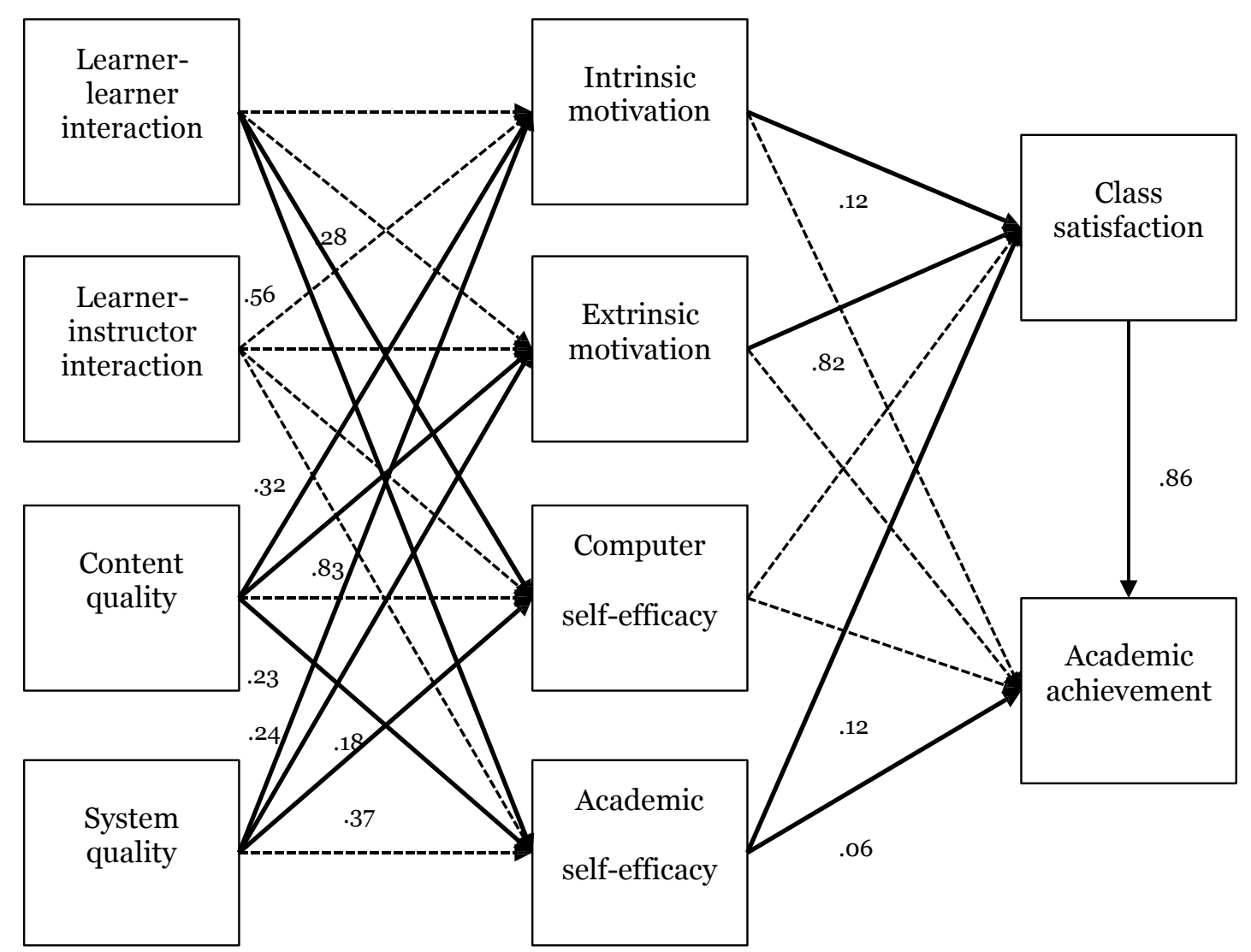

Figure 1. Standardized path coefficients for the modified model.

Table 4 shows the direct, indirect and total effects for the research model. First, content quality was found to be the most influential determinant for intrinsic motivation, with a total effect of .322. This was followed by system quality, with a total effect of .240. Second, content quality was found to be the most influential determinant for extrinsic motivation, with a total effect of .827. This was followed by system quality, with a total effect of .167. Third, system quality was found to be the most influential determinant for computer self-efficacy, with a total effect of .372. This was followed by learner-learner interaction, with a total effect of .277. Fourth, system quality was found to be the most influential determinant for academic self-efficacy, with a total effect of .560. This was followed by content quality, with a total effect of .232. Fifth, extrinsic motivation was the most influential determinant forclass satisfaction, with a total effect of .816. This was followed by content quality, system quality, intrinsic motivation, academic self-efficacy and with a total effect of $.768, .180, .115, .115$ and .o64 respectively. Sixth, extrinsic motivation was the most influential determinant for academic achievemen, with a total effect of .883 . This was followed by class satisfaction, content quality, system quality, and intrinsic 
motivation with a total effect of $.863, .755, .174$ and .111 respectively.

Table 4

Direct, Indirect, and Total Effects for the Research Model (A->B)

\begin{tabular}{|c|c|c|c|c|c|c|c|c|c|}
\hline \multirow{2}{*}{$\begin{array}{l}\text { B } \\
\text { A }\end{array}$} & \multicolumn{3}{|c|}{ IM } & \multicolumn{3}{|c|}{ EM } & \multicolumn{3}{|c|}{ CSE } \\
\hline & Direct & Indirect & Total & Direct & Indirect & Total & Direct & Indirect & Total \\
\hline LLI & & & & & & & $.277^{*}$ & & $.277^{*}$ \\
\hline CQ & $.322^{*}$ & & $.322^{*}$ & $.827^{*}$ & & $.827^{*}$ & & & \\
\hline SQ & $.240^{*}$ & & $.240^{*}$ & $.167^{*}$ & & $.167^{*}$ & $.372^{*}$ & & $.372^{*}$ \\
\hline \multicolumn{10}{|l|}{ IM } \\
\hline \multicolumn{10}{|l|}{ EM } \\
\hline \multicolumn{10}{|l|}{ ASE } \\
\hline \multicolumn{10}{|l|}{$\mathrm{CS}$} \\
\hline B & & ASE & & & CS & & & $\mathrm{AA}$ & \\
\hline $\mathrm{A}$ & Direct & Indirect & Total & Direct & Indirect & Total & Direct & Indirect & Total \\
\hline LLI & & & & & $.064^{*}$ & $.064^{*}$ & & .027 & .027 \\
\hline $\mathrm{CQ}$ & $.232^{*}$ & & $.232^{*}$ & & $.768^{*}$ & $.768^{*}$ & & $.755^{*}$ & $.755^{*}$ \\
\hline SQ & $.560^{*}$ & & $.560^{*}$ & & $.180^{*}$ & $.180^{*}$ & & $.174^{*}$ & $.174^{*}$ \\
\hline IM & & & & $.115^{*}$ & & $.115^{*}$ & & $.111^{*}$ & $.111^{*}$ \\
\hline EM & & & & $.816^{*}$ & & $.816^{*}$ & & $.883^{*}$ & $.883^{*}$ \\
\hline ASE & & & & $.115^{*}$ & & $.115^{*}$ & $.063^{*}$ & & .047 \\
\hline CS & & & & . & & & $.863^{*}$ & & $.863^{*}$ \\
\hline
\end{tabular}




\section{Discussion and Conclusion}

As the e-learning industry has developed in recent years, cyber universities have expressed increased interest in improving online learning methodologies. This study sought to understand the effects of various environmental and individual constructs on the effectiveness of e-learning in a Korean context. The descriptive statistics indicated relatively limited interaction among learners or between instructors and learners. Moreover, the interaction constructs did not significantly affect motivation or self-efficacy, with the exception of learner-learner interaction's effect on computer and academic self-efficacy. Therefore, interactions should be promoted that have a proven and substantial impact on learning outcomes. Moreover, the development of optimal instructional strategies for facilitating communication, as well as the active use of such strategies, is essential.

Content quality and system quality were significant in terms of eliciting intrinsic and extrinsic motivation. Furthermore, academic self-efficacy and computer self-efficacy were affected by content quality and system quality, respectively. These results indicate that high quality learning content and learning systems lead to increased learning motivation. Additionally, stable and user-friendly system interfaces contributed to higher levels of computer self-efficacy, while rich and relevant learning content boosted academic self-efficacy.

Although intrinsic and extrinsic motivation directly influenced class satisfaction, these variables did not do so for academic achievement. With regard to class satisfaction and academic achievement, academic self-efficacy was found to be significant while computer self-efficacy was not.. Academic achievement was influenced by class satisfaction, which is consistent with general beliefs wherein significant correlations were found between satisfaction and academic achievement (Kang \& Park, 2010). As for indirect effects, learner-learner interaction, content quality, and system quality exhibited a significant indirect effect on class satisfaction; learner-learner interaction, content quality, system quality, internal motivation, and external motivation exhibited an indirect effect on academic achievement.

Generally, most variables had common significance in terms of learning results, including class satisfaction and academic achievement. Nevertheless, learner-instructor interaction and computer self-efficacy were less statistically important than exogenous variables in the study's research setting. This finding was to some extent expected given the descriptive statistics and Korean educational culture, wherein instructors still commonly teach in a unidirectional manner with limited studentteacher or student-student interaction. Moreover, since participants possessed a sufficient degree of computer literacy, computer self-efficacy was not likely to affect variables related to e-learning significantly.

Based on these results, we provide the following suggestions for future research and teaching practices. First, when assessing e-learning effectiveness, environmental and personal factors should be considered, as well as the complicated relationship between them. Accordingly, approaches to instructional design should consider the dynamics between such factors. Second, the results indicated that there was limited significance between interactions, particularly between instructors and learners. Although some interactions were identified that seemed to reflect Korean cultural traditions and educational practices, these interactions were nonetheless ineffective from a learning standpoint. 
Hence, subsequent research should investigate how interactivity can be enhanced both quantitatively and quantitatively.

Third, despite generally high scores for computer self-efficacy, the variable did not exhibit an effect on academic achievement or class satisfaction. This implies that the participants were computer literate, and that the construct had little to no impact on learning outcomes. Therefore, research concerning digital competency in Korean e-learning must go a step beyond the issue of computer literacy such as how learners strategically use computers for enhancing learning effects, etc.. Fourth, e-learning institutions should exert continuous effort toward enhancing teaching effectiveness, and in doing so consider the significance of the variables and relationships discussed in this study. Indeed, since there are numerous interrelated variables in e-learning, it is important to focus on those most relevant to effectiveness and efficiency. Finally, future research should examine the precise effects of cultural context on e-learning effectiveness.

\section{Acknowledgements}

This study was funded by Konkuk University in 2014.

\section{References}

An, B. K. (2008). Development of evaluation criteria for interactions in e-learning for public schools (Unpublished doctoral dissertation). Keimyung University, Daegu, Korea.

Astin, A. (1991). Assessment for excellence: The philosophy and practice of assessment and evaluation in higher education. New York: Macmillan.

Bandura, A. (1993). Perceived self-efficacy in cognitive development and functioning. Educational Psychologist, 28(2), 117-148. doi:10.1207/s15326985ep2802_3

BeSuccess (2014, February 25). Korea stands out in Asia as a key test market for global tech companies. e27. Retrieved from http://e27.co/korea-stands-out-in-asia-as-a-key-test-marketfor-global-tech-companies-including-facebook/

Chemers, M. M., Hu, L. T., \& Garcia, B. F. (2001). Academic self-efficacy and first-year college student performance and adjustment. Journal of Educational Psychology, 93(1), 55-64. doi:10.1037/0022-0663.93.1.55

Chiu, C. M., \& Wang, E. T. G. (2008). Understanding web-based learning continuance intention: the role of subjective task value. Information \& Management, 45, 194-201.

doi:10.1016/j.im.2008.02.003

Choi, E. J., \& Choi, M. S. (2016). A meta-analysis on the impact of different e-learning interactions on learning effect. Journal of Educational Technology, 32(1), 139-164. 
doi:10.17232/KSET.32.1.139

Korean Council for Online Universities. (2014a). History of Cyber University. Retrieved from http://www.cuinfo.net/home/intro/yearHistory.sub.action?gnb=114

Korean Council for Online Universities. (2014b). Statistics of Cyber University (Agency statistics reports). Retrieved from http://www.cuinfo.net/home/eudc/statistics.sub.action?gnb=55

DeLone, W. H., \& McLean, E. R. (1992). Information systems success: The quest for the dependent variable. Information Systems Research, 3(1), 60-86. doi:10.1287/isre.3.1.60

DeLone, W. H., \& McLean, E. R. (2003). The DeLone and McLean model of information systems success: A ten year update. Journal of Management Information Systems, 19(4), 9-30. doi:10.1080/07421222.2003.11045748

Elliot, A. J. (2005). A conceptual history of the achievement goals construct. In A. J. Elliot \& C. S. Dweck (Eds.), Handbook of competence and motivation (pp. 52-84). London: Guildford Press.

Eom, S. B. (2011). Relationships among e-Learning systems and e-Learning outcomes: A path analysis model. Human Systems Management, 30(4), 229-241. doi:10.3233/HSM-2011-0752

Flowers, L. O. (2011). Exploring HBCU student academic self-efficacy in online STEM courses. The Journal of Human Resource and Adult Learning, 7(2), 139-145.

Fornell, C., \& Larcker, D. F. (1981). Evaluating structural equation models with unobservable and measurement error. Journal of Marketing Research, 18(1), 39-50. doi:10.2307/3151312

Gu, J. C., Lee, S. C., Kim, N. H., \& Suh, Y. H. (2006). Factors affecting user acceptance in mobile banking: An empirical study using extended tam and trust. Journal of Management \& Information, 16(2), 159-181. Retrieved from http://www.earticle.net.oca.korea.ac.kr/article.aspx?sn=90903

Hirumi, A. "2c". (2013). Three levels of planned eLearning interactions: A framework for grounding research and the design of eLearning programs. Quarterly Review of Distance Education, 14(1), 1-16.

Holsapple, C. W., \& Lee-Post, A. (2006). Defining, assessing and promoting e-Learning success: An information systems perspective. Decision Sciences Journal of Innovative Education, 4(1), 6785. doi:10.1111/j.1540-4609.2006.00102.x

Høigaard, R., Kovac`, V. B., Øverby, N. C., \& Haugen, T. (2015). Academic self-efficacy mediates the effects of school psychological climate on academic achievement. School Psychology Quarterly, 3o(1), 64-74. doi:10.1037/spq0oooo56

Hsiao, H., Tu, Y., \& Chung, H. (2012). Perceived social supports, computer self-efficacy, and computer use among high school students. Turkish Online Journal of Educational Technology,11(2), 167-177. 
Hwang, S. J. (2004). Educational problems and alternative solutions of Korean high school: The case of Geochang high school (Unpublished master thesis). Kookmin University, Seoul, Korea.

Johnson, R. D., Hornik, S., \& Salas, E. (2008). An empirical examination of factors contributing to the creation of successful e-learning environments. International Journal of Human-Computer Studies, 66(5), 356-369. doi:10.1016/j.ijhcs.2007.11.003

Kang, M., \& Park, I. (2010). The exploratory empirical study of learners' perceived interaction factor model between learner and instructor in e-learning environments. Journal of Educational Technology, 26(2), 187-215. Retrieved from http://www.kset.or.kr/sub.php?code $=02$ soci010601\&mode=view\&no=266\&category=\&page $=13 \&$ search $=\&$ keyword $=$

Kang, M., \& Lim, K. (2013). Structural analyses on the effects of self-regulated learning and learning motivation on learner-instructor interactions and academic performance in college learning environments with e-learning contents. Journal of the Korea Contents Society, 13(11), 10141023. doi:10.5392/JKCA2013.13.11.1014

Kettinger, J. W., \& Lee, L. L. (1997). Pragmatic perspectives on the measurement of information systems service quality. MIS Quarterly, 21(2), 223-240. doi:10.2307/249421

Kjelgaard, M. M., \& Guarino, A. J. (2012). Assessing the predictive validity of the admission process in a master's level speech language pathology program. Psychological Reports: Measures \& Statistics, 111(2), 613-617. doi:10.2466/03.15.28.PRo.111.5.613-617

Korean Ministry of Education (2013). Education information white paper in 2012. Retrieved from http://lib.keris.or.kr/bbs/content/6_1515

Lee, K. H. (2010). A Study on the activation of mathematical creativity education for education of private education (Unpublished master thesis). Ewha Women University, Seoul, Korea.

Lee, Y. C. (2006). An empirical investigation into factors influencing the adoption of an e-learning system. Online Information Review, 3o(5), 517-541. doi:10.1108/14684520610706406

Lee, Y. W., Strong, D. M., Kahn, B. K., \& Wang, R. Y. (2002). AIMQ: a methodology for information quality assessment. Information \& Management, 4O, 133-146. doi:10.1016/So3787206(02)00043-5

Lin, K., Chen, N., \& Fang, K. (2011). Understanding e-learning continuance intention: a negative critical incidents perspective. Behaviour \& Information Technology, 30(1), 77-89. doi:10.1080/01449291003752948

Nehme, M. (2010). E-learning and students' motivation. Legal Education Review, 2O(1/2), 223-239.

Organization for Economic Co-operation and Development. (2013). Fixed (wired) broadband penetration, historical leaders [Data file]. Retrieved from 
http://www.oecd.org/sti/broadband/1h-BBPenetrationHistorical-Top5-2013-06.xls

Park, C. S. (2006). (A) study on the improvement of corporal punishment for students (Unpublished master thesis). Daegu Education University. Daegu, Korea.

Piccoli, G., Ahmad, R., \& Ives, B. (2001). Web-based virtual learning environments: A research framework and a preliminary assessment of effectiveness in basic IT skills training. MIS Quarterly, 25(4). 401-426. doi:10.2307/3250989

Putwain, D. W., \& Symes, W. (2012). Are low competence beliefs always associated with high test anxiety? The mediating role of achievement goals. British Journal of Educational Psychology, 82(2), 207-224.

Segars, A. H., \& Grover, V. (1998). Strategic information systems planning success: An investigation of the construct and its measurement. MIS Quarterly, 22(2), 139-163. doi:10.2307/249393

Simmering, M. J., Posey, C., \& Piccoli, G. (2009). Computer self-efficacy and motivation to learning in a self-directed online course. Decision Sciences Journal of Innovative Education, 7(1), 99-121. doi:10.1111/j.1540-4609.2008.00207.x

Stein, J. J. (1997). Asynchronous computer conferencing as a supplement to classroom instruction in higher education: The impact of selected learner characteristics on user satisfaction and the amount of interaction (Unpublished doctoral dissertation). Wayne State University, Michigan, the United States.

Womble, J. (2008). E-learning: the relationship among learner satisfaction, self-efficacy, and usefulness. The Business Review, 10(1), 182-188.

Wang, Y. S. (2003). Assessment of learner satisfaction with asynchronous electronic learning systems. Information \& Management, 41(1), 75-86. doi:10.1016/So378-7206(03)00028-4

Wong, W., \& Huang, N. N. (2011). The effects of e-learning system service quality and users' acceptance on organizational learning. International Journal of Business \& Information, 6(2), 205-225.

Athabasca

University

(0) 